\title{
Gastroschisis and omphalocele in Finland in the 1970s: prevalence at birth and its correlates
}

\author{
K HEMMINKI, ${ }^{1}$ I SALONIEMI, ${ }^{1}$ P KYYRÖNEN, ${ }^{1}$ AND M KEKOMÄKI ${ }^{2}$ \\ From the Institute of Occupational Health, ${ }^{1}$ SF-00290 Helsinki 29, and the Department of Paediatrics, ${ }^{2}$ \\ University of Turku, SF-20520 Turku 52, Finland
}

SUMMARY Information on liveborn and stillborn children with gastroschisis and omphalocele was collected from hospital and register sources in Finland from 1970 to 1979. The apparent prevalence of gastroschisis at birth increased from $0.77 / 10000$ births in $1970-4$ to $1.42 / 10000$ in 1975-9. The prevalence of omphalocele (1.96/10 000) was unchanged during the decade. Even for gastroschisis the apparent increase in prevalence was noted for northern Finland only, while for southern Finland the prevalence has been stable during the 1970s, possibly suggesting diagnostic or reporting differences between various parts of the country. Some correlates of increased risk of gastroschisis included: low birth weight, low maternal age, urban residence, and maternal employment in commercial and sales work.

Gastroschisis and omphalocele are the two most common congenital defects of the abdominal wall presenting as neonatal surgical emergencies. Omphalocele has been recognised for a long time, whereas gastroschisis has only recently become a separate diagnosis. ${ }^{1}$ By 1961 only 31 cases of gastroschisis had been reported, ${ }^{2}$ but the number of patients described since has been increasing considerably. ${ }^{34}$

Contrary to what was once thought, the clinical differences between gastroschisis and omphalocele are not limited to intestinal herniation, located at the base of the umbilical cord in the case of omphalocele, and lateral to the umbilicus in the case of gastroschisis. Additional anomalies and chromosomal aberrations are much less common in cases of gastroschisis than of omphalocele. ${ }^{5}$ Furthermore, important anomalies are infrequent in families of probands having gastroschisis in contrast to those having omphalocele. Familial gastroschisis has been described, but it is very rare. ${ }^{6}$ These facts not only emphasise the difference between gastroschisis and omphalocele, they also suggest that gastroschisis could be caused by some type of intrauterine injury to a genotypically normal conceptus, probably before the physiological closure of the abdominal wall at the tenth week of gestation. This exceptional hypothesis has not stimulated much research on the aetiology of gastroschisis.

The Nordic Working Group on Occupational Reproductive Hazards undertook a study of gastroschisis and omphalocele in Denmark, Finland, Norway, and Sweden to explore possible reasons for the apparent increase in the prevalence of gastroschisis. The results from Finland are reported here; some results from Sweden ${ }^{4}$ and from Norway ${ }^{7}$ have already been published.

\section{Material and methods}

Information on the cases of gastroschisis and omphalocele was primarily for 1970-9 but some information for 1964-9 was used in table 1. The data were collected from the Finnish Register of Congenital Malformations, ${ }^{8}{ }^{8}$ death certificates, and from the journals of university clinics.

Information was sought about the patient (birth date, sex, weight, gestation time, types of malformations), the mother (age, parity, occupation, community of residence), and the father (age, occupation).

Table 1 Finland 1964-79: some characteristics of babies with gastroschisis and those with omphalocele and their mothers compared with all births. (Number of cases with relevant information in parentheses)

\begin{tabular}{|c|c|c|c|}
\hline Character & Gastroschisis & Omphalocele & All births \\
\hline $\begin{array}{l}\text { Mean birth weight (g) } \\
\text { M/F ratio } \\
\text { Mean maternal age (y) } \\
\text { No of cases }\end{array}$ & $\begin{array}{ll}2490 & (65) * * * \\
1.44 & (78) \\
22.5 & (68)^{* * *} \\
81 & \end{array}$ & $\begin{array}{ll}2860 & (100) * \cdots \\
1 \cdot 32 & (151) \\
27 \cdot 3 & (130) \\
154 & \end{array}$ & $\begin{array}{l}3450 \\
1 \cdot 05 \\
26 \cdot 1 \\
633135\end{array}$ \\
\hline
\end{tabular}

"**Difference between groups of malformation and all births statistically significant $(p<0.001)$. 
The data on births were collected from two sources - the official statistics of Finland, published by the Central Statistical Office of Finland, and the computerised register of all inpatients discharged from general hospitals.

The prevalence at birth was calculated per number of liveborn and stillborn babies. Four different standardised prevalences were calculated using the direct method of standardisation. The yearly prevalence, the prevalence by the mother's occupation, and the prevalence by parity were standardised to the age of all Finnish women who gave birth in the same year. The prevalences in different age groups were standardised to the parity of the child according to all births in Finland in the same year. Statistical significance was determined by the $\chi^{2}$-test, the Mantel-Haenszel test, and by the test involving normal distribution. The $\chi^{2}$-test was used when trends were tested.

\section{Results}

The birth prevalence of gastroschisis increased steadily in Finland during the 1970s (fig 1), the prevlaence was $0 \cdot 77 / 10000$ births in $1970-4$ and $1.42 / 10000$ in $1975-9$, resulting in a mean prevalence of $1 \cdot 09 / 10000$ for the whole decade. The difference in the prevalence between the two five-year periods was significant statistically $(p<0.05$, Mantel-Haenszel test). By contrast, the prevalence of omphalocele remained constant throughout the decade with age standardised prevalence was $0 \cdot 77 / 10000$ births in $1970-4$ and $1 \cdot 90 / 10000$ for the latter half of the decade, yielding a mean prevalence of $1 \cdot 96 / 10000$.

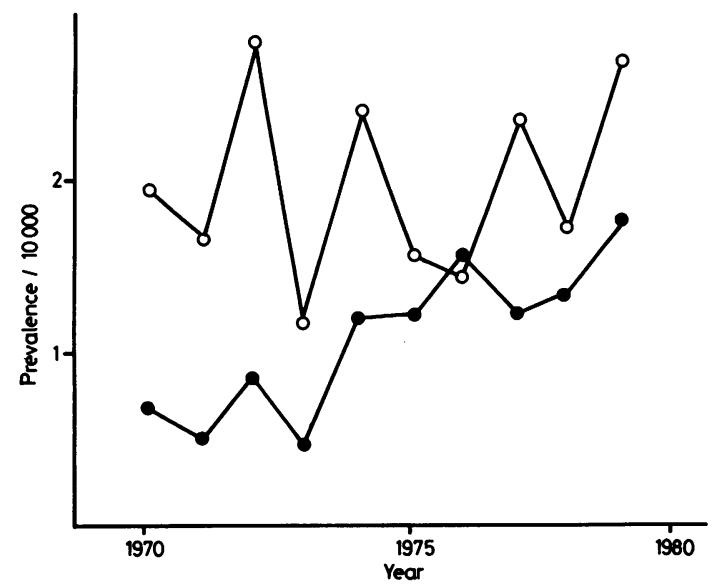

Fig 1 Prevalence of gastroschisis (- -) and of omphalocele $\left(-\bigcirc^{-}\right)$in Finland 1970-9, standardised for maternal age.
Some characteristics of the malformed child and of the mother are given in table 1 . The birth weights of the babies with gastroschisis were lower than those of the babies with omphalocele, whose birth weights in turn were lower than those of all liveborn children in Finland. Boys were more frequent among the cases of gastroschisis than among either the cases of omphalocele or all babies born in Finland. The maternal age was young for the gastroschisis births (22.5 years) compared with all births $(26 \cdot 1)$ or to the omphalocele births $(27 \cdot 3)$.

The birth prevalence of gastroschisis decreased with the increasing age of the mother, whereas that of omphalocele increased, irrespective of whether the data were standardised for parity (fig 2). The trend by age was highly significant for gastroschisis and non-significant for omphalocele.

In crude data the effect of parity appeared to follow that of the maternal age. Age-standardisation, however, changed the relative prevalence. A

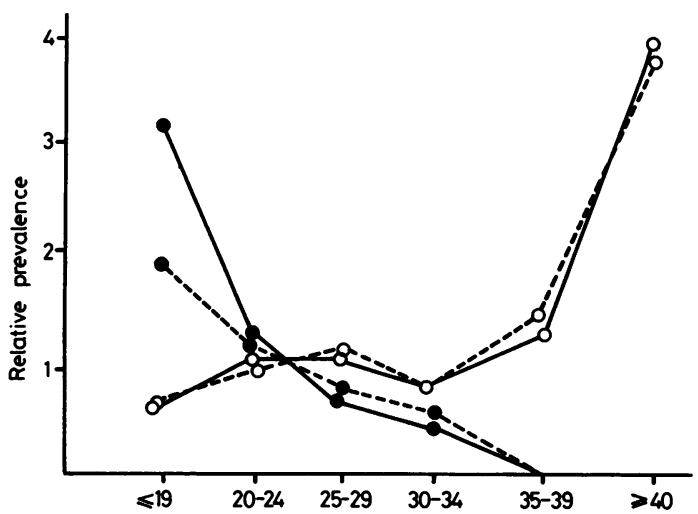

Fig 2 Relative crude prevalence of gastroschisis (- -) and omphalocele $\left(-\bigcirc_{-}\right)$by maternal age, and corresponding prevalences, standardised for parity, of all Finnish births 1970-9 (-- -).

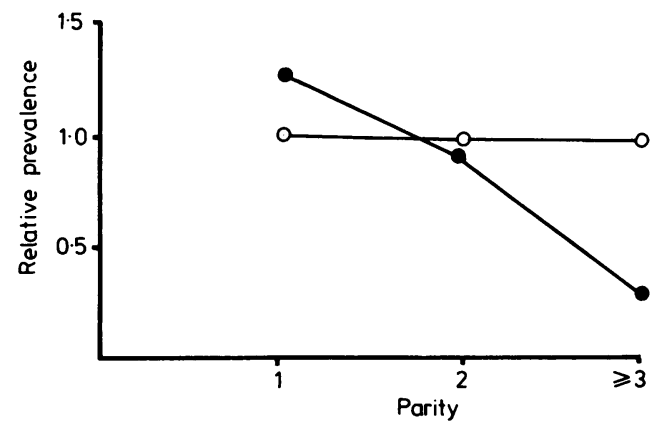

Fig 3 Relative prevalence of gastroschisis (- -) and omphalocele (- $\left.\bigcirc_{-}\right)$by parity, standardised for maternal age. 
decreasing trend (non-significant in trend analysis) was still observed for the prevalence of gastroschisis with increasing parity, whereas the effect of parity for omphalocele was completely abolished by age-standardisation (fig 3 ).

The distributions of gastroschisis and omphalocele were calculated for urban and rural communities. The prevalence of gastroschisis was 1.32 in urban communities and 0.74 per 10000 births in rural communities, a difference that was statistically significant $(p<0.05)$, but the prevalence of omphalocele in urban and rural communities was identical at 1.96 per 10000 births. The concentration of cases of gastroschisis in urban communities remained statistically significant after standardisation for maternal age (table 2). The highest regional prevalences for gastroschisis were recorded for the southern province around Helsinki (Uusimaa, relative prevalence 1.41) and for a rather northern province (Oulu, relative prevalence $1 \cdot 32$ ). The lowest regional prevalences for gastroschisis were recorded in rural central Finland.

Table 2 Finland 1970-9: prevalence of gastroschisis in urban and rural districts relative to all districts, standardised for age

\begin{tabular}{|c|c|c|c|c|}
\hline \multirow[b]{2}{*}{ Area } & \multicolumn{2}{|c|}{ Urban } & \multicolumn{2}{|c|}{ Rural } \\
\hline & No & $\begin{array}{l}\text { Relative } \\
\text { prevalence }\end{array}$ & No & $\begin{array}{l}\text { Relative } \\
\text { prevalence }\end{array}$ \\
\hline $\begin{array}{l}\text { All Finland } \\
\text { Southern Finland } \\
\text { Northern Finland }\end{array}$ & $\begin{array}{l}46 \\
35 \\
11\end{array}$ & $\begin{array}{l}1.21^{*} \\
1 \cdot 34 \\
0.85\end{array}$ & $\begin{array}{r}16 \\
9 \\
7\end{array}$ & $\begin{array}{l}0.65^{*} \\
0.91 \\
0.50\end{array}$ \\
\hline
\end{tabular}

$x^{i}=4.31 \quad p<0.05$.

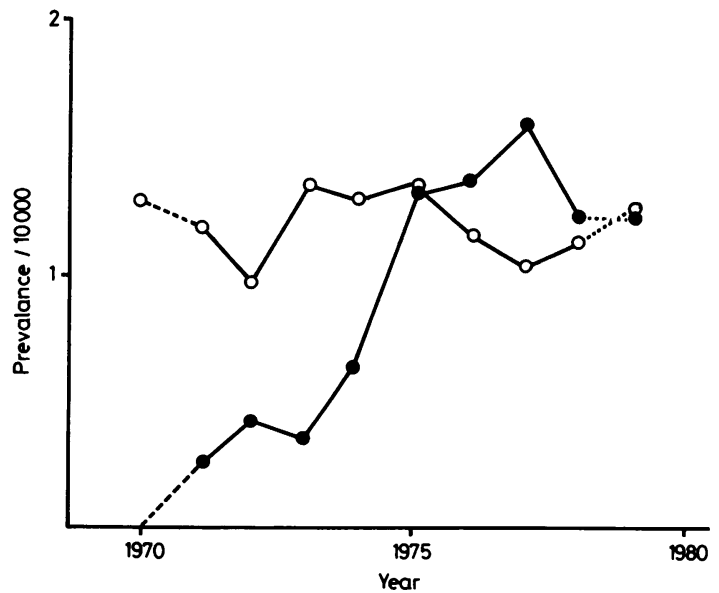

Fig 4 Prevalence of gastroschisis (three-year moving average) in southern (-O-) and in northern Finland $(-)$. Interrupted lines indicate averages based on under three years.
Because the prevalence of gastroschisis appeared to vary by region, particularly in the early part of the 1970 s, the annual prevalences (in three-year running averages) were plotted separately for the industrialised south and for the rural north (fig 4). It was quite striking that the increase in prevalence for all of Finland was mainly due to the increase in northern Finland.

To test whether the observed urban-rural difference in the prevalence of gastroschisis could be explained only by the preferential ascertainment of cases from urbanised southern Finland, the urban-rural prevalences were calculated separately for southern and northern Finland for 1976-9, when the prevalence in the north had reached that of the south; the relative prevalences in the urban areas was 1.21 and in the rural areas 0.68 , so that the urban-rural difference was observed in 1976-9. Thus the observed south-north difference failed to explain the observed urban-rural difference in the prevalence of gastroschisis.

It has been suggested that the Swedish data on gastroschisis point to a cohort effect-that is, the increased prevalence is peculiar to a specific birth cohort of women. The proposal was tested with the Finnish data in two quinquennia (table 3 ). The mean age of all childbearing women was increasing during the 1970s. The increase in age was only slightly higher for the mother and babies with gastroschisis. Thus the present series did not show a clear cohort effect. The increase in the age for the mothers of babies with gastroschisis could be noted both in southern and northern Finland, although the increase was slightly higher for southern Finland (table 3).

Seasonal prevalences of the two malformations were apparently different (table 4 ). The prevalence of gastroschisis was highest for children born in the early part of the year while that of omphalocele did not deviate from the distribution of all births.

Data on the maternal occupations of the babies with gastroschisis or omphalocele were available for $62 \%$ and $55 \%$ of the cases, respectively. Allowing for these low figures, commercial and sales work was

Table 3 Finland 1970-4 and 1975-9: mean maternal age of all mothers and mothers of babies with gastroschisis

\begin{tabular}{llll}
\hline Area & $1970-4$ & $1975-9$ & Increase \\
\hline All Finland & & & \\
All births & 26.1 & 27.0 & 0.9 \\
Births with gastroschisis & 21.2 & 22.8 & 1.6 \\
Northern Finland & 26.4 & 26.8 & 0.4 \\
All births & 21.0 & 21.1 & 0.1 \\
Births with gastroschisis & 26.0 & 27.1 & 1.1 \\
Southern Finland & 21.3 & 23.5 & 2.2 \\
All births & \\
Births with gastroschisis & 21.5 &
\end{tabular}

Using $t$ tests none of the increases were statistically significant $(p>0.05)$. 
Table 4 Seasonal variation in the occurrence of gastroschisis and omphalocele

\begin{tabular}{|c|c|c|c|c|c|c|}
\hline \multirow[b]{2}{*}{ Period of birth } & \multicolumn{2}{|c|}{ Gastroschisis } & \multicolumn{2}{|c|}{ Omphalocele } & \multicolumn{2}{|l|}{ All births } \\
\hline & No & $\%$ & No & $\%$ & No & $\%$ \\
\hline $\begin{array}{l}\text { January-April } \\
\text { May-August } \\
\text { September-December } \\
\text { Missing date }\end{array}$ & $\begin{array}{r}27 \\
24 \\
13 \\
5\end{array}$ & $\begin{array}{l}42 \cdot 2 \\
37 \cdot 5 \\
20 \cdot 3^{*} \\
-\end{array}$ & $\begin{array}{r}39 \\
38 \\
38 \\
9\end{array}$ & $\begin{array}{l}33 \cdot 6 \\
33 \cdot 2 \\
33 \cdot 2 \\
-\end{array}$ & $\begin{array}{l}217259 \\
216040 \\
199836 \\
-\end{array}$ & $\begin{array}{l}34 \cdot 3 \\
34 \cdot 1 \\
31 \cdot 6 \\
-\end{array}$ \\
\hline
\end{tabular}

overrepresented in the age-standardised gastroschisis series; service work was slightly overrepresented both in the gastroschisis and omphalocele series. Economically inactive women (housewives and farmers' wives) were clearly underrepresented in both series, particularly in the gastroschisis series, where the relative prevalence was $0 \cdot 41$. No identified maternal occupation was in the printing industry.

\section{Discussion}

The Nordic Working Group on Occupational Reproductive Hazards organised a study on gastroschisis because previous hospital-based ${ }^{10-13}$ and register-based ${ }^{4}$ studies have suggested an increase in the prevalence of gastroschisis. If not explained by changes in diagnostic or registration practice the reported increase would be among the most drastic changes noted for the registered types of malformations in the Nordic countries. Several ecological variables were chosen for the study to provide explanations for the apparent increase in the prevalence. A parallel study was carried out with another malformation of the abdominal wall, omphalocele, as the diagnostic distinction between the two types of malformation might not have been very clear earlier. The given diagnoses were scrutinised with special care, but in many cases the lack of a complete description of the malformation made reassessment of the diagnosis impossible.

The prevalence for Finland showed a consistent increase for gastroschisis. which increased from $0 \cdot 77 / 10000$ in the first half of the 1970 s to 1.42 in the second half, whereas the rate for omphalocele was stable throughout the 1970s. Both the trends and the absolute rates were quite similar to the Norwegian figures. ${ }^{7}$ In Sweden the prevalence of gastroschisis, which agrees with the present overall figures; increased till the middle of the 1970s, since when it has been decreasing (B Källén, personal communication). In the United States the reported prevalence of gastroschisis $(1 \cdot 59 / 10000)$ is higher for the years of 1962-74 than the Nordic rates for the same period. ${ }^{13}$
The prevalence of gastroschisis was higher in the wealthier southern part of Finland than in the poorer northern part, whereas no such regional differences were found for omphalocele. It was striking that a pronounced increase in the annual prevalence of gastroschisis was noted only for northern Finland; the rate has remained uniform for southern Finland. Although the increase in the intensity of some harmful factors in northern Finland cannot be excluded, the data suggest that the increased prevalence in Finland may be explained by improved diagnostic or registration accuracy, particularly in northern Finland. In a small-scale Swedish case-control study, the distribution of some factors (such as smoking, alcohol consumption, the use of drugs, and contraceptive methods) did not differ between the cases and the controls (S Lindham, 1981 , personal communication).

The present study confirmed the results of several other studies on the age-dependent probability of bearing a child with gastroschisis or omphalocele: for gastroschisis young women and for omphalocele old women appeared to be at particular risk..$^{3414}$ Low parity also appeared to be a risk indicator for gastroschisis, while parity appeared to have no effect on omphalocele after age-standardisation.

Some ecological variables appeared to correlate with the prevalence of gastroschisis but not with that of omphalocele. There were more cases of gastroschisis in urban communities than in rural communities, and more babies with gastroschisis were born to sales personnel and fewer to economically inactive women (housewives and farmers' wives) than to all working women. No mother in either series was employed in the printing industry, which has been overrepresented in an American series. ${ }^{15}$ Although the present findings may not be directly related to the aetiological factors of gastroschisis, they provide clues for further studies on possible underlying environmental factors.

We thank the members of the Nordic Working Group on Occupational Reproductive Hazards for the exchange of information.

\section{References}

${ }^{1}$ Moore T, Stokes GF. Gastroschisis. Surgery 1953; 33: 112-20.

${ }^{2}$ Moore T. Gastroschisis with antenatal evisceration of intestines and urinary bladder. Ann Surg 1963; 158: 263-9.

${ }^{3}$ Moore T. Gastroschisis and omphalocele: clinical differences. Surgery 1977; 82: 561-8. 
${ }^{4}$ Lindham S. Omphalocele and gastroschisis in Sweden 1965-1970. Acta Paediatr Scand 1981; 70: 55-60.

${ }^{5}$ Noordijk JA, Bloesmsma-Jonkman F. Gastroschisis: no myth. J Pediatr Surg 1978; 13: 47-9.

'Salinas CF, Bartoshesky L, Othersen HB, Lepae L, Feingold M, Jorgensen RJ. Familial occurrence of gastroschisis. Four new cases and review of the literature. Am J Dis Child 1979; 133: 514-7.

${ }^{7}$ Egenaes J, Bjerkedal T. Forekomst av gastroschisis og omphalocele i Norge 1967-1979. Tidsskr Nor Laegeforen (in press).

${ }^{8}$ Saxén L, Klemetti A, Härö AS. A matched pair register for studies of selected congenital defects. Am J Epidemiol 1974; 100: 297-306.

${ }^{9}$ Hemminki K, Mutanen P, Saloniemi I, Luoma K. Congenital malformations and maternal occupations in Finland: multivariate analysis. J Epidemiol Community Health 1981: 35: 5-10.
${ }^{10}$ Gierup J, Lundkvist K. Gastroschisis-a pilot study of its incidence and the possible influence of teratogenic factors. Zeitschrift für Kinderchirurgie und Grenzgebiete 1979; 28: 39-42.

${ }^{11}$ Knutrud O, Bjordal RI, Rø J, Bø G. Gastroschisis and omphalocele, causes of postoperative death in children. Baltimore, Munich: Urban and Schwanzeberg, 1979: 51-61.

${ }^{12}$ Kekomäki M, Louhimo I. Gastroschisis and omphalocele (Finnish). Duodecim 1979; 95: 73-80.

${ }^{13}$ Colombani PM, Cunninham D. Perinatal aspects of omphalocele and gastroschisis. Am J Dis Child 1977; 131: $1386-8$

${ }^{14}$ McKeown T, MacMahon B, Record RG. An investigation of 69 cases of exomphalos. Am J Hum Genet 1953; 5: 168-75.

${ }^{15}$ Erickson JD, Cochran WM, Anderson CE. Birth defects and printing. Lancet 1978; i: 385. 